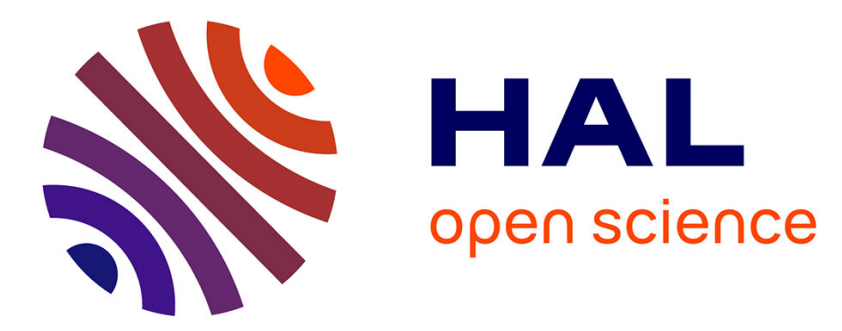

\title{
A Survey on Quality of Service Monitoring and Analysis of Network of Agricultural Science and Technology Resources
}

\author{
Ma Jian
}

\section{- To cite this version:}

Ma Jian. A Survey on Quality of Service Monitoring and Analysis of Network of Agricultural Science and Technology Resources. 8th International Conference on Computer and Computing Technologies in Agriculture (CCTA), Sep 2014, Beijing, China. pp.515-520, 10.1007/978-3-319-19620-6_58 . hal01420317

\section{HAL Id: hal-01420317 \\ https://hal.inria.fr/hal-01420317}

Submitted on 20 Dec 2016

HAL is a multi-disciplinary open access archive for the deposit and dissemination of scientific research documents, whether they are published or not. The documents may come from teaching and research institutions in France or abroad, or from public or private research centers.
L'archive ouverte pluridisciplinaire HAL, est destinée au dépôt et à la diffusion de documents scientifiques de niveau recherche, publiés ou non, émanant des établissements d'enseignement et de recherche français ou étrangers, des laboratoires publics ou privés.

\section{(c)(1)}

Distributed under a Creative Commons Attribution| 4.0 International License 


\title{
A survey on Quality of Service Monitoring and Analysis of Network of Agricultural Science and Technology Resources
}

\author{
Ma $\operatorname{Jian}^{1 \mathrm{a}}$ \\ ${ }^{1}$ Agricultural Information Institute of Chinese Academy of Agricultural Sciences, Beijing, $100081 ;{ }^{2}$ Key \\ Laboratory of Agricultural Information Service Technology (2006-2010), Ministry of Agriculture, The People's \\ Republic of China, Beijing, 100081 \\ a majian@caas.cn
}

\begin{abstract}
First, current situation on Network of agricultural science and technology resources is described. Then we pay much attention to the quality of service monitoring and analysis system of network resources. And finally, we come to the conclusion that the construction of Quality of service monitoring, analysis of network of agricultural science and technology resources is in great need.
\end{abstract}

Keyword: Network of agricultural science and technology resources, Quality of Service, Monitoring

\section{1 the introduction}

Now all kinds of agricultural science and technology resources website has walked into people's life, has gradually become an indispensable part of People's Daily life, people began to used to agricultural science and technology resource information from the Internet. With the speeding up of the society informatization process, people's concerns of the websites of the agricultural science and technology resources are changing, from the initial focus on the website of system quality and the quality of website information gradually shifted to focus on the website service quality, focus on the website and its management ability and willingness to meet user needs. For agricultural science and technology resources website service quality monitoring, analysis and assessment, and can make a website manager timely understanding and diagnosis of the problems existing in the service, in order to promote the service level of the website to provide theoretical basis and data support, has important practical significance.

Research and development "network of agricultural science and technology resources service quality monitoring, analysis and evaluation system" is the purpose of automatically to be monitored website 
service quality monitoring and analysis, so that you can image, intuitive, accurate and timely of monitoring objects, monitoring index and monitoring methods, analysis methods, assessment mechanism for centralized control and management, such as security for performance of agricultural science and technology web site.

This article will systematically elaborate network of agricultural science and technology resources service quality related concepts, theories, methods and evaluation system. Subsequent content is organized as follows: section 2 is about the network current situation of the development of agricultural science and technology resources; Section 3 summarizes the current monitoring of the quality of service of technology; Finally, section 4 of this article are summarized.

\section{2 current situation of the development of network of agricultural science and technology resources}

At present, the agricultural websites have takes on an increase in number, rich content gradually, and huge potential for development of good posture. From 1994, the ministry of agriculture information center was the first to create "China's agricultural information website", the development of Chinese agricultural informatization construction has made great strides. According to the ministry of agriculture information center, agricultural websites in China is only 2200 at the end of 2002. In the year to December 2010 agricultural websites in China for more than 30 thousands, more than the developed countries such as France, Canada, China agricultural website has become the world's top ten.

This paper involved in agricultural science and technology resources is mainly refers to the government agriculture website. Government agriculture website refers to the competent department of agriculture to provide agricultural information to the public in the Internet, the Internet, interaction, and other personalized services platform. At present, the proportion of government web site is on the decline, this is caused by two reasons, one is because of government web sites around the increasingly standardized, integrating multiple websites together. The second is due to the websites of the agricultural enterprises, such as media site number increasing.

Although network of agricultural science and technology resources development situation is good, but there are many problems in developing: 
(1) duplicate information, practicality is not strong

On the agricultural website in the content construction of our country exist a degree of repetition. One is due to a lack of unified planning of redundant construction problem, many sites have "regulations" column, its content is typically include China farm law, etc repeat information content. Another is due to the easy replication of network information, many websites will be other agricultural website copy and release of information.

Agricultural information services and the interests of the farmers lack of close contact and targeted, supply and demand of agricultural market information dissemination is not enough; The depth of the information resources development and utilization is not enough, directly related to the local agricultural information share is small, and the prospective predictive information is significant.

(2) the agricultural information standard not unified, difficult to Shared resources

Our country agriculture information resource distribution in different areas and departments, each management main body is according to their own work need to identify the information source, information collecting ways and presentation. Different sources of agricultural information due to a lack of specification, lost the foundation of communication and sharing. Between agricultural management departments, administrative departments of agriculture and frequent, complicated information between production and sales department can't realize the resource sharing, information exchange is often blocked, it is difficult to develop and integrate across departments of agricultural information resources.

(3) the site of utilization rate is not high, not attractive enough to farmers

In August 2009, the average agricultural class web site visitors online time is 5.81 seconds, It show that the majority of visitors for a short stay in agricultural sites, visitors is not interested in most of the content of the site . 


\section{3 network resources service quality monitoring technology}

\section{1 monitoring technology overview}

Abroad in the field of network information search, monitor, start early, developing very quickly. Among them, the United States in this area has been in a leading position, in addition to the established military "joint secret - computer network defense system" JTF - CND and the government of the federal intrusion detection network "FIDNet", at the moment, is to build the global Internet for text, voice and image search analysis of comprehensive information monitoring system. Information world powers are analysis of network information search technology is adopted to establish the government monitoring infrastructure, finance and other key industry. Many foreign companies are actively research and develop this kind of technology and products. German Cobion company launched network image analysis techniques in 2003, such as: more information visual character recognition, face detection and recognition and so on, has established the Europe's largest network information gathering analysis center. In network quality of service technology research, a Web client and the HTTP request to provide a performance guarantee and service differentiation technology, Web service quality arises at the historic moment, and get more and more attention in scholars and businesses, become a new research field of quality of service technology and important academic branches. The research progress on the network quality of service, so far very rapidly, and has made many fundamental progress. Distributed network measurement infrastructure (DNMAI) is customized according to user demand survey and analysis solutions, provides customizable user interface functions, reached the international advanced level. IBM Tivoli Web Response Monitor can capture the end user experience on the performance of web-based applications. It measuring response time, URL information and so on.

In the field of network quality of service in China started late, but the government attaches great importance to it, and formulated a series of measures for the administration. Many scientific research institutions, army, enterprise, introduced a number of products, and good results have been achieved. Some companies in China in recent years have been introduced with the network information search technology related products, such as: Shanghai fudan guanghua company, guangdong Morgan company, Beijing capital industrial technology development company, Beijing sharp Ann company, 
launched network security monitoring products. But the product application scope is relatively single, difficult to adapt to the development of network information security domain at present.

The development of the domestic network monitoring technology mainly in the 1999 years later, and technology to focus on firewalls and network intrusion detection, for the contents of the information monitoring only simple seal on site, not to mention for the monitoring of network information service quality, in this aspect is almost blank. In this aspect of the monitoring can ensure the security of network and information, optimize the efficiency of information, strengthen the competitiveness of various aspects.

\section{2 monitoring tool}

According to the different of installing and measuring method of the monitoring software,the Internet monitoring method can be divided into the monitoring based on the server and client based monitoring two types.

At present, the vast majority of monitoring software are based on the server, the user buy the software, install it on the local server, for the performance of the local server, database and other hardware and software of the monitoring. The benefits of the monitoring software is that users can understand their local machine efficiency, also can understand the local network connection and some e-business processes at the local implementation. But the disadvantage is that can't reflect directly to the end user login web site and use of e-commerce services. Now offers the software company has many, like Freshwater, BMC, and CA.

At present domestic widely used monitoring method is based on the monitoring on the server. Domestic monitoring technology mainly oriented network performance test and speed of network monitoring, monitoring service way is mainly based on the monitoring agent, in this way, the monitoring agent is installed on a network server, monitoring agent specific monitoring tasks. Advantages of this approach is that powerful, able to monitor to the system of internal error; Stable operation, high reliability; The disadvantage is : due to the need to install to each machine running, so the maintenance cost is high; Run in the interior of the online services, rather than the client, so can't reflect all sorts of problems caused by network problems. 
With the development of Internet technology and the transformation of the management concept, there is a new kind of monitoring service. The monitoring service is the software installed on the client, not installed on the network operators' local server. From the perspective of end users on the network monitoring, search a network bottlenecks. Using the principle of this monitoring service fundamentally embodies the user-centered management thought, because for the end user, when to log in, they don't care about network operators are using the HP servers or IBM servers, is NT operation platform, or Unix operating platform, also don't care about their use of database is Oracle database or Microsoft. Abroad have this kind of monitoring service have more in-depth research, domestic research on this aspect is less.

\section{4 concludes}

Through the above research discussion, we can draw the following conclusion:

(1) network in our country agriculture science and technology resources have been gradually takes on an increase in number, content rich, the good situation of the development potential is huge, but many problems still exist in the process of development, such as information repeated, practicality is not strong, difficult to share resources, the use of the website's utilization rate is not high, not attractive enough for their users, etc.

(2) abroad in the field of network information search, monitor, start early, developing very quickly. In this field in China starts late, although the government attaches great importance to it, and a series of basic management measures had maked, many scientific research institutions, army, enterprises introduced a number of products, and good results have been achieved, but the application scope is relatively single, difficult to adapt to the development of network information security domain at present.

Therefore, the online resources of agricultural science and technology Service quality monitoring, analysis System construction has been on the agenda, Through monitoring and analysis, can pray for the important role for the healthy development of the websites of the agricultural science and technology . 


\section{ACKNOWLEDGEMENTS}

The work is supported by the Academy of Science and Technology for Development fund project "int elligent search-based Tibet science \& technology information resource sharing technology” , the Natio nal Science and Technology Major Project of the Ministry of Science and Technology of China (Grant No. 2009ZX03001-019-01), and the special fund project for Basic Science Research Business Fee, AII (No. 2010-J-07).

\section{reference}

[1] FIDNet. http://www.privacilla.org/government/fidnet.html

[2] IBM Tivoli Web Response Monitor and IBM Tivoli Web Segment Analyzer. http://publib.boulder.ibm.com/tividd/td/ITPathWRMon/fixpack120/en_US/PDF/wrm_wsa_20_fixpackIF0003. pdf

[3] Freshwater. http://www.freshwater-uk.com/

[4] BMC. http://www.bmc.com/

[5] CA. http://www.ca.com/us/default.aspx

[6] Richmond Betsy. Ten C's For Evaluating Internet Sources[EB] http:// www. montgo merycollege.edu/Departments/writegt/htmlhandouts/Ten C internet sources. Htm

[7] Paolo Atzeni ,Paolo Merialdo,Giuseppe Sindoni. Web Site Evaluation: Methodology and Case Study

[8] Robert Harris. Evaluating Internet Research Sources[EB]. http://www.virtualsalt. com /evalu8it.htm

[9] Joy Tillotson. Web Site Evaluation: A Survey of Undergraduates [J]:Online Information Review,2002(6)

[10] Franz Barjak, Xuemei Li and Mike Thelwall. Which Factors Explain the Web Impact of Scientists Personal Homepages? Journal of the American Society for Information Science and Technology, 2007,58(2):200-211 